\title{
Chitobiase, A New Reporter Enzyme
}

BioTechniques 25:1030-1035 (December 1998)

\section{D.Y. Kalabat, J.M. Froelich, T.K. Phuong, R.A. Forsyth, V.G. Newman and J.W. Zyskind}

San Diego State University, San Diego, CA, USA

\section{INTRODUCTION}

The most popular reporter enzyme in bacteria is $\beta$-galactosidase ( $\beta$-gal), but because it is present in bacteria such as Escherichia coli, deletions of the lac $Z$ gene must be constructed before its use. We chose to develop $N, N^{\prime}$ diacetylchitobiase (chitobiase) $(\beta-N$ acetyl-D-glucosaminidase, EC 3.2.1. 30) as a reporter enzyme because its activity and that of the less specific $\mathrm{N}$ acetyl- $\beta$-D-glucosaminidase, are missing in E. coli strains. Cellular chitobiase activity can be measured quantitatively and monitored using blue/white colony indicator plates. Substrates for this enzyme, chitobiose, $p$-nitrophenyl- $N$-acetyl- $\beta$-D-glucosaminide (PNAG) (Sigma Chemical, St. Louis, MO, USA) and 5-bromo-4chloro-3-indolyl- $N$-acetyl- $\beta$-D-glucosaminide (X-Gluc) (Sigma Chemical) are commercially available.

Chitobiase is one of two enzymes that hydrolyze chitin, an abundant insoluble polysaccharide, to its monomeric unit, $N$-acetylglucosamine (GlcNac). In E. coli cells harboring a plasmid carrying the gene encoding chitobiase $(c h b)$ from the marine bacterium, Vibrio harveyi, the enzyme is associated with the outer membrane $(11,17)$. Chitobiase activity is located in the cytoplasm in cells containing a fusion between the pUC19 $\alpha$-peptide of $\beta$-gal and the carboxy-terminus of chitobiase (11). The vectors we describe here contain this fusion (11), which is deleted for the signal sequence of chitobiase.

Reporter-enzyme activity originating from high-copy number plasmids can vary due to differences in copy number or to titration of regulator pro- teins. For this reason, fusions often are integrated into the chromosome for single-copy analysis of promoter activity using lambda vectors. Because the size of lambda vectors makes them inconvenient for cloning, and in vitro packaging of lambda vectors is time-consuming, a simplified $\lambda$ site-specific recombination system was developed (7). Two new vectors described here allow the use of this $\lambda$ site-specific recombination system for single-copy analysis. In addition to the $\lambda$ attP site, the vectors contain a region of pUC19 (18) including the lac promoter, a multiple cloning site and the amino-terminal sequence of the $\alpha$ peptide of $\beta$-gal that is fused in-frame to the carboxy-terminal end of chitobiase, deleted for its signal sequence. Using appropriate restriction enzymes, the lac promoter in these plasmids can be replaced with other promoters to create in-frame fusions with the chitobiase gene.

To test $c h b$ as a reporter gene, we replaced the lac promoter with the dnaA operon regulatory region $(10,12)$ and created in-frame fusions between an amino-terminal fragment of DnaA and chitobiase. The chitobiase activities of these fusions matched the $\beta$-gal levels obtained with similar fusions between the $d n a A$ regulatory region and the $l a c Z$ reporter gene.

\section{MATERIALS AND METHODS}

\section{Construction of Vectors}

Polymerase chain reaction (PCR) products were frequently cloned first at the SmaI or EcoRV restriction sites of plasmid pBluescript ${ }^{\circledR}$ II (pKSII+; Strat- 
agene, La Jolla, CA, USA). The nucleotide sequence of all PCR products was determined by the Microchemical Core Facility (San Diego State University, San Diego, CA, USA). Unmethylated plasmid DNA, isolated from an $E$. coli dam $^{-}$strain when cutting with the $B c l$ I enzyme, was required.

pDYK9 was constructed by (i) ligating a SphI-KpnI PCR product containing the dnaA promoter region into pRSG196 (11), also cut with SphI and KpnI. Plasmid pAC17 (5) served as a template with primers 5'-GCA CAT GCA TGC TGG TCA TTA AAT TTT CC-3' and 5'-CGG GGT ACC AAC TCA TCC TGC AAT CG-3', producing a PCR product 374-bp long that contains 353-bp from the $d n a A$ promoter region (bases 583-935, numbering according to Reference 10). The forward primer (SphI primer II) contained an $S p h \mathrm{I}$ site, and the reverse primer (KpnI primer) contained a KpnI site for cloning. This created an in-frame fusion between the amino-terminal 17 amino acids (aa) of DnaA and the carboxy-terminal end of chitobiase, deleted for the amino-terminal 22 aa including the signal peptide. (ii) The 3270-bp DraIHindIII (partial digest) fragment containing the $d n a A-c h b$ fusion was ligated to the pACYC184 (4) 2555-bp HincIIHindIII fragment carrying chloramphenicol-resistance $\left(\mathrm{Cm}^{\mathrm{r}}\right)$ and the P15A origin. (iii) A NotI site was introduced at the AccI site after digestion with AccI, treatment with Mung bean nuclease and ligation to phosphorylated NotI linkers (NEBL). (iv) A NotI site was introduced at the Ase I site after digestion with AseI, treatment with Mung bean nuclease and ligation to NEBL. (v) An $X b a \mathrm{I}-S p h \mathrm{I}$ PCR product containing the rrnBt1t2 terminator was ligated into this plasmid cut with the same enzymes creating pDYK7. E. coli chromosomal DNA served as a template with primers 5'-CTA GTC TAG ATG CCG AAC TCA GAA GTG A-3' and 5'-GCA CAT GCA TGC GGG GGA TGG CTT GTA GAT-3' to produce a PCR product 357 bp long that contains bases 6534-6869 from the $r r n B$ operon (numbering according to Reference 3) and includes the complex transcription-termination region of this operon (15). The forward primer contained an $X b a I$ site, and the reverse primer contained an $S p h I$ site. (vi) A BclI-SmaI PCR product containing the $\lambda$ attP site was ligated into pDYK7, cut with Tth1111, treated with Mung bean nuclease and then digested with BclI. Plasmid pHN894 (9) served as a template with the forward primer 5'-CAT GAT CAT GCG ACA GGT TTG ATG A-3' and the reverse primer 5'-GGG GGC GCC TAC CTT TCA CGA G-3', producing a PCR product 466-bp long that contains the $\lambda$ attP site. The 466-bp PCR product containing the $\lambda$ attP site was first cloned into the SmaI site of the pKSII+ plasmid to produce $\mathrm{pDYK} 8$. The forward primer contains a $B c l I$ site, and the reverse primer contains $G^{\prime}$ 's at the $5^{\prime}$ end to recreate a $S m a$ I site when cloning the PCR fragment into a SmaI site. This PCR product includes bases -211 to +241 from the center of the attP core and the sequence required for optimum $\lambda$ att $P$ site integration (14). The orientation of attP is such that when the fusion is integrated at $a t t B$, the transcription direction of dnaApl and $p 2$ promoters is the same as replication fork movement mimicking the orientation at the wildtype (WT) dnaA promoters.

pDYK11 was constructed by ligating an SphI-KpnI PCR product containing the $r p m H-d n a A$ promoter region into pDYK9 also digested with $S p h \mathrm{I}$ and KpnI. Plasmid pAC17 (5) served as a template with the primers 5'-CAT GCA TGC ATG AAA CGA TGG ACA CC-3' and 5'-CGG GGT ACC AAC TCA TCC TGC AAT CG-3' to produce a PCR product 616-bp long that contains 598 bp from the rpmHdnaA regulatory region (bases 338935, numbering according to Reference 10). The forward primer (SphI primer I) contained an $S p h \mathrm{I}$ site, and the reverse primer (KpnI primer) contained a KpnI site for cloning.

pJMF3 was constructed by first ligating an AseI linker (5'-CATTAATGCATG-3' self-hybridized) into the SphI site of pDYK11. The pUC19 (18) AseI$K p n I$ fragment containing the lacPOpolylinker region was ligated to this plasmid after digestion with AseI and $K p n I$. The resulting in-frame fusion between the amino-terminal 21 aa of the pUC19 lacZ $\alpha$ peptide (18) and the carboxy-terminal end of chitobiase, deleted for the amino-terminal 22 aa is identical to the protein fusion in pRSG196 (11).
pJMF4 was constructed by $(i)$ ligating the BamHI-EcoRV fragment of pDYK8 containing the $\lambda$ attP site into pDYK7 that had been digested with Tth1111, treated with Mung bean nuclease and then digested with $B c l$, to create $\mathrm{pTKP} 9$. This reversed the orientation of the attP site relative to the attP site in pDYK9. (ii) The pDYK11 BspMII-KpnI fragment containing the rpmH-dnaA promoter region was ligated into pTKP9, digested with the same enzymes, to create pTKP11. This reversed the orientation of the attP site relative to the attP site in pDYK11. (iii) An AseI linker (5'-CATTAATGCATG3 ' self-hybridized) was ligated into the SphI site of pTKP11 to create pJMF2. The pUC19 (18) AseI-KpnI fragment containing the $l a c P O$-polylinker region was ligated to pJMF2, cut with AseI and KpnI to create pJMF4.

\section{Strains}

The E. coli strains used in this study are described in Table 1.

\section{Site-Specific Recombination}

To move the chitobiase fusions in pDYK9 and pDYK11 to the $a t t B$ site in the chromosome, NotI fragments from these plasmids were self-ligated and transformed (19) or electroporated into strain WM2269 (DH5 $\alpha$ containing pLDR8) (7). Plasmid pLDR8 (7) expresses integrase from the $\lambda P_{\mathrm{R}}$ promoter and contains the $\lambda c \mathrm{I}_{857}$ repressor gene, a kanamycin-resistance gene and a temperature-sensitive origin of replication. The transformed or electroporated cells were incubated at $42^{\circ} \mathrm{C}$ with shaking for $30 \mathrm{~min}$ then moved to $37^{\circ} \mathrm{C}$ for $1 \mathrm{~h}$, followed by selection on LB agar plates containing chloramphenicol $(25 \mu \mathrm{g} / \mathrm{mL})$ at $42^{\circ} \mathrm{C}$. Transformants were screened for loss of kanamycin-resistance and therefore loss of pLDR8.

\section{Bacteriophage P1 Transduction}

Transduction with $\mathrm{P} 1$ bacteriophage (19) was used to construct strains and to confirm the chromosomal location of the $d n a A-c h b$ fusions. Co-transduction of $\mathrm{Cm}^{\mathrm{r}}$ (carried by the fusion) and galK (linked to $a t t B$ ) indicated that $\mathrm{Cm}^{\mathrm{r}}$ and 
Table 1. E. coli K-12 Strains

\begin{tabular}{|c|c|c|}
\hline Strain & Genotype/Phenotype & Source/Reference \\
\hline RB220 & $\begin{array}{l}\text { גRB1(dnaA-lacZ fusion) his } \Delta(\text { lac }) \times 74 \text { proA rspL supF81(Ts) } \\
\text { thi tsx trp }(\mathrm{Am})\end{array}$ & A. Wright (2) \\
\hline TP220 & RB220 fis::767(Km) & (8) \\
\hline MG1655 & $\lambda-F^{-}$ & E. coli Genetic Stock Center \\
\hline RJ1799 & MG1655 fis::985 (Sper/Strr) & R. Johnson (1) \\
\hline DYK11W & MG1655 rpmH-dnaA-chb fusion at attB & This work \\
\hline DYK11F & RJ1799 rpmH-dnaA-chb fusion at attB & $\begin{array}{l}\text { This work (rpmH-dnaA-chb fusion } \\
\text { transferred by } \mathrm{P} 1 \text {-mediated transduction } \\
\text { from DYK11W to RJ1799) }\end{array}$ \\
\hline DYK9W & MG1655 dnaA-chb fusion at attB & This work \\
\hline DYK9F & RJ1799 dnaA-chb fusion at attB & $\begin{array}{l}\text { This work (dnaA-chb fusion transferred } \\
\text { by P1-mediated transduction from } \\
\text { DYK9W to RJ1799) }\end{array}$ \\
\hline $\mathrm{DH} 5 \alpha$ & $\begin{array}{l}\mathrm{F}^{-} \Phi 80 \alpha \text { lacZAM15 } \Delta(\text { lacZYA-argF)U169 endA1 hsdR17 deoR } \\
\text { supE44 thi-1 recA1 gyrA96 relA1 }\end{array}$ & Our laboratory \\
\hline WM2269 & DH5 $\alpha$ containing pLDR8 & W. Messer (7) \\
\hline
\end{tabular}

galK are linked on the chromosomes of strains DYK9W, DYK9F, DYK11W and DYK11F.

\section{Chitobiase Assays}

Because chitobiase activity is located in the cytoplasm, when its signal peptide is replaced by fusion with another peptide, assays are performed on toluenetreated cells (12) and washed once with M9 salts (12). Chitobiase activity is determined with PNAG as the substrate $(11,16)$ with the following modifications. The assays contain toluenized cells in chitobiase buffer $(10 \mathrm{mM}$ Tris$\mathrm{HCl}, \mathrm{pH} 8.0$ and $0.5 \mathrm{M} \mathrm{NaCl}$ ) and 666 $\mu \mathrm{M}$ PNAG. $\mathrm{NaCl}$ is included because chitobiase has approximately $80 \%$ full activity in the absence of salt, with maximal activity occurring between 0.25 and $0.6 \mathrm{M} \mathrm{NaCl}$. Toluenized cells $(0.772$ $\mathrm{mL}$ ) are preincubated at $28^{\circ} \mathrm{C}$, and the reaction is started with the addition of $0.228 \mathrm{~mL}$ PNAG $(1 \mathrm{mg} / \mathrm{mL})$. After incubation at $28^{\circ} \mathrm{C}$, the reaction is stopped by the addition of $1 \mathrm{~mL}$ of $1 \mathrm{M}$ Tris-base. The release of $p$-nitrophenol is measured at $400 \mathrm{~nm}$ and turbidity at $550 \mathrm{~nm}$. $p$-Nitrophenol release is measured immediately at $400 \mathrm{~nm}$ with a molar absorptivity of $18 \times 10^{3} \mathrm{~L} / \mathrm{mol} / \mathrm{cm}$. Units are calculated after subtracting the light-scatter- ing factor $\left[1.5 \times\right.$ optical density $\left.(\mathrm{OD})_{550}\right]$ from $\mathrm{OD}_{400}$ of the sample. The normalizing factor of 1.5 was determined previously by measuring the light-scattering ratio of bacteria at $\mathrm{OD}_{400}$ and $\mathrm{OD}_{550}$. One unit of chitobiase activity is the amount of enzyme that catalyzes the formation of $1 \mathrm{pmol} / \mathrm{min}$ of $p$-nitrophenol at $28^{\circ} \mathrm{C}$. For comparison to Miller units of $\beta$-gal (13), the units are normalized to $1 \mathrm{~mL}$ of culture at $\mathrm{OD}_{450}=1$.

\section{RESULTS}

\section{Plasmid Vectors Containing the lac Promoter-Chitobiase Fusion and the $\lambda$ attP Site}

Plasmids pJMF3 and pJMF4 (Figure 1) contain the $l a c P O$ promoter with the first 21 aa of $l a c Z \alpha$ (from pUC19) fused in-frame to the $c h b$ gene. These plasmids also contain the $\lambda$ phage $a t t P$ recombination site in different orientations, the gene encoding chloramphenicol acetyltransferase (cat) and a ribosomal terminator, rrnBtlt2, inserted upstream of the lac-chb fusion to prevent read-through from other promoters. The chitobiase activity associated with these plasmids (Table 2) is high in the absence of isopropyl-thio- $\beta$-D- galactoside (IPTG) because of titration of lac repressor expressed from a single-copy chromosomal gene. Induction by IPTG is approximately 10 -fold (Table 2).

The lac promoter can be replaced with another promoter, and a fusion protein created with chitobiase, by cutting with $S p h \mathrm{I}$ or AseI and either SalI,

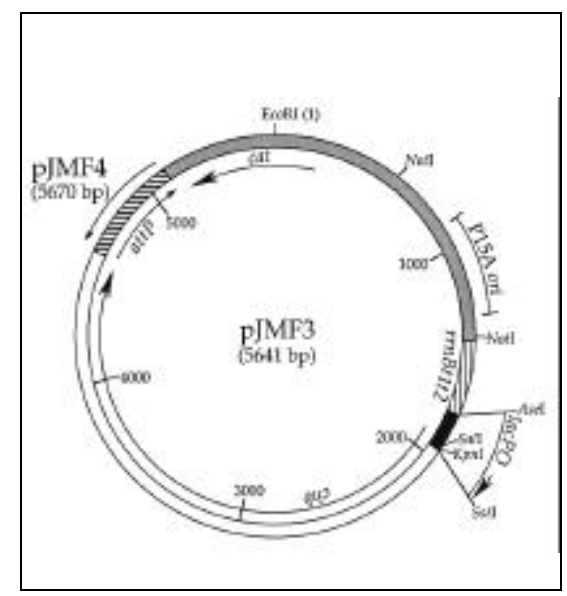

Figure 1. Plasmids pJMF3 and pJMF4 containing $a t t P$ in 2 different orientations and the lac promoter with the first 21 aa of lacZ $\alpha$ (from pUC19) fused in-frame to the $c h b$ gene. Construction of these plasmids is described in Materials and Methods. Sequence of fusion region is shown in Figure 2. Restriction sites shown are found once in the plasmid sequences except for NotI, which has 2 sites flanking the P15A origin. 
Table 2. Chitobiase Activity of lacZ-chb Fusiona

\begin{tabular}{|lcc|}
\hline & \multicolumn{2}{c|}{ Chitobiase $^{\text {b }}$ (Uc) } \\
\cline { 2 - 3 } Plasmid & -IPTG & +IPTG (1 mM) \\
\hline pJMF3 in DH5 $\alpha$ & $668 \pm 45$ & $9320 \pm 347$ \\
pJMF4 in DH5 $\alpha$ & $788 \pm 44$ & $7188 \pm 477$ \\
aOvernight cultures were diluted 1:1000 into $50 \mathrm{~mL}$ prewarmed LB and grown to \\
OD $450=0.1 .1$ mM IPTG was added to half of the culture, and growth continued \\
to OD $450=0.3$. \\
bTriplicate samples were assayed. Mean chitobiase activities are given with stan- \\
dard deviations. \\
cOne unit of chitobiase activity is 1 pmol of $p$-nitrophenol/min at $28^{\circ} \mathrm{C}$. Units given \\
for 1 mL of culture at $\mathrm{OD}_{450}=1$.
\end{tabular}

KpnI or SstI (Figure 2). Fusions created with these vectors can be moved to the chromosome by site-specific recombination at the $\lambda a t t B$ site to permit single-copy analysis of the activity of the promoter. The protocol (7) involves two components, (i) a circular DNA containing the $\lambda$ attachment site, attP, the promoter-chb gene fusion and the cat gene and (ii) a helper plasmid, pLDR8 (7), which contains the int gene under the control of the temperaturesensitive repressor, $\mathrm{cI} 857$ and a temperature-sensitive origin of replication. The plasmid is digested with NotI to remove the P15A origin, and the fragment containing the chitobiase fusion is self-ligated before transformation into cells containing pLDR8. Integration occurs by site-specific recombination between $a t t P$ and $a t t B$ (17.4 min on the E. coli chromosome) (Figure 3).

\section{Use of the Chitobiase Reporter Enzyme to Study dnaA Gene Regulation}

Two plasmids, pDYK9 and pDYK11, were constructed to assess the regulation of the $d n a A$ gene using chitobiase as a reporter enzyme. These plasmids differ by the absence of the rpmH regulatory region in $\mathrm{pDYK} 9$ (Figure 4). These fusions were moved from the plasmid to the chromosomal $a t t B$ site for single-copy analysis as described above. After transformation of strain WM2269 with the ligated DNA, integration occurred by site-specific recombination between the attP and the $a t t B$ sites. The orientation of attP in pDYK9 and pDYK11 is such that when the fusion is integrated at $a t t B$, the transcription direction of dnaApl and $d n a A p 2$ promoters is the same as move-

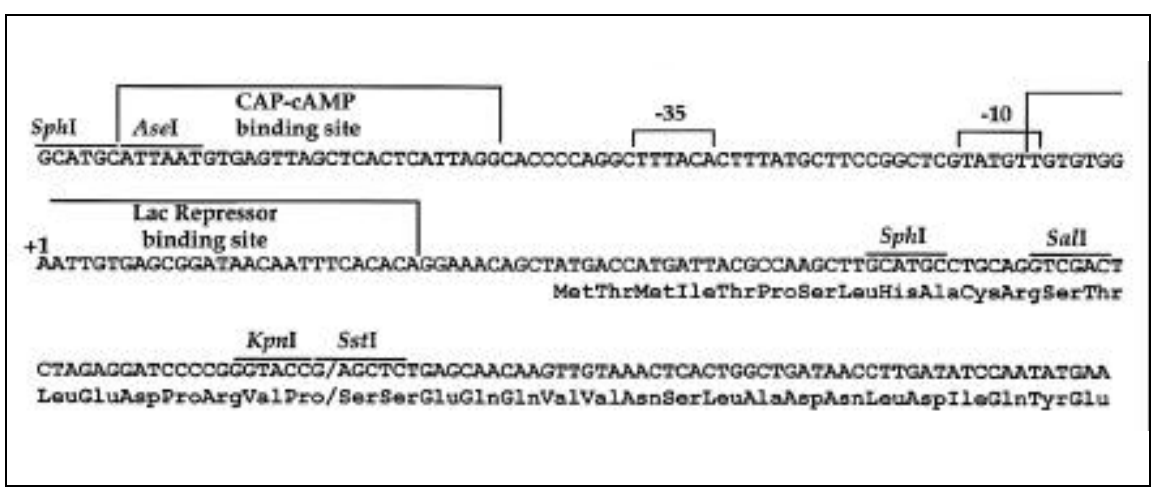

Figure 2. Sequence of the lac promoter and the chitobiase fusion found in pJMF3 and pJMF4 (see Figure 1). Fusion between lacZ $\alpha$ (from pUC19) and $c h b(16)$ is indicated by (/); start of transcription is indicated by $(+1)$. Sequence and binding sites in the lac promoter regulatory region are found in Reference 6. Restriction enzyme sites shown are found once in the plasmid sequences except for $S p h \mathrm{I}$, which has 2 sites; these different restriction sites can be used to replace the lac promoter with another promoter together with part of a coding region to produce an in-frame fusion with $c h b$. 
ment of the replication fork. This orientation is the same as at the $d n a A$ WT location. The genetic location of the fusions was confirmed in the $\mathrm{Cm}^{\mathrm{r}}$ transformants by demonstrating cotransduction of $\mathrm{Cm}^{\mathrm{r}}$ and galK.

The fusions created in strain WM2269 were moved by P1 transduction to MG1655, creating strain DYK9W with pDYK9 and strain DYK11W with pDYK11. Deletion of the rpmH promoters had very little effect (1.4fold) on chitobiase activity (Table 3, compare lines 1 and 3 ).

Fis protein binds to a site in the dnaAp2 promoter that covers the -35 sequence (Figure 5) and appears to be a repressor of DnaA expression. A fusion protein with $\beta$-gal activity that is expressed from the $r p m H$-dnaA regulatory region has increased $\beta$-gal activity (1.9-fold) in a fis ${ }^{-}$mutant when compared to Fis WT cells (Reference 8; data shown in Table 3). Similarly, the absence of Fis leads to a greater than 2fold increase in chitobiase activity of the DnaA-chitobiase fusion protein for the DYK9F and DYK11F strains, comparable in extent to that observed with the dnaA-lacZ fusion strain, TP220 (Table 3).

Table 3. Chitobiase and $\beta$-Gal Activities of dnaA-chb and dnaA-lacZ Fusions in WT and fis Mutant Backgrounds

\begin{tabular}{|c|c|c|}
\hline Strains & Chitobiase $^{a}\left(U^{b}\right)$ & $\begin{array}{c}\beta \text {-Galc } \\
(\text { Miller Ud) }\end{array}$ \\
\hline DYK11W fis ${ }^{+}$ & $30.0 \pm 2.1$ & \\
\hline DYK11F fis::985 & $80.0 \pm 1.2$ & \\
\hline DYK9W fis $^{+}$ & $44.0 \pm 2.1$ & \\
\hline DYK9F fis::985 & $96.0 \pm 3.5$ & \\
\hline RB220 fis $^{+}$ & & $59.8 \pm 7.9$ \\
\hline TP220 fis::767 & & $115.2 \pm 7.2$ \\
\hline \multicolumn{3}{|c|}{$\begin{array}{l}\text { aTriplicate samples were assayed during exponential growth. Mean chitobiase } \\
\text { activities are given with standard deviation. }\end{array}$} \\
\hline \multicolumn{3}{|c|}{$\begin{array}{l}\text { bOne unit of chitobiase activity is } 1 \mathrm{pmol} \text { of } p \text {-nitrophenol per min at } 28^{\circ} \mathrm{C} \text {. Units } \\
\text { given for } 1 \mathrm{~mL} \text { of culture at } \mathrm{OD}_{450}=1 \text {. }\end{array}$} \\
\hline
\end{tabular}

\section{DISCUSSION}

Chitobiase is a useful reporter enzyme because many species of bacteria, including $E$. coli, do not synthesize this enzyme. To test whether chitobiase could be used as a reporter enzyme in other bacteria or eukaryotic cells, add

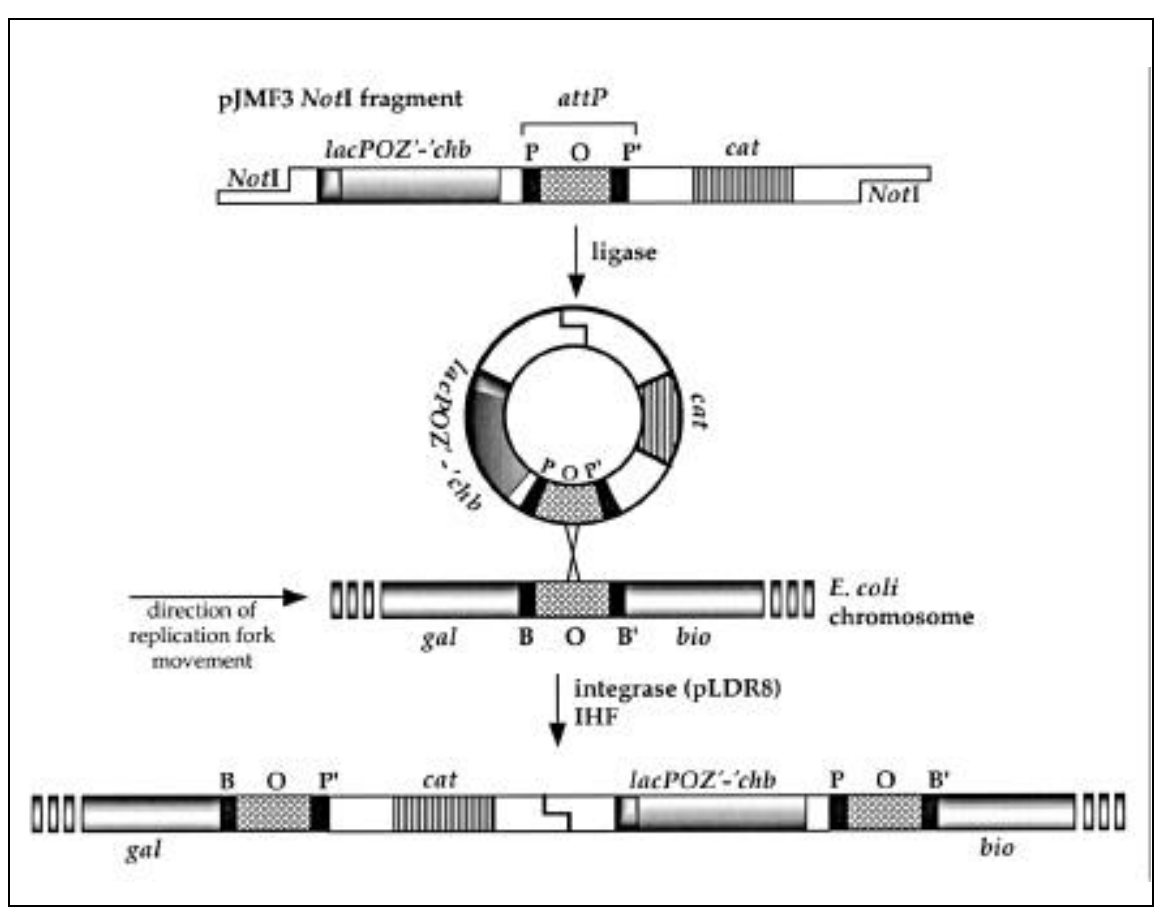

Figure 3. Integration of $\boldsymbol{c h b}$ fusions into the chromosome by site-specific recombination between $\boldsymbol{a t t} \boldsymbol{B}$ and $\boldsymbol{a t t P}$. The steps involved are described in Materials and Methods and Reference 7.
PNAG to cells and look for the appearance of yellow color. Also, chitobiase is useful as a reporter enzyme because no mutations or deletions need to be created in bacterial host strains that lack this enzyme. To identify regulators of the expression of a promoter, chb reporter fusions can be moved using P1 bacteriophage transduction to strains deleted for suspected regulatory genes. Such

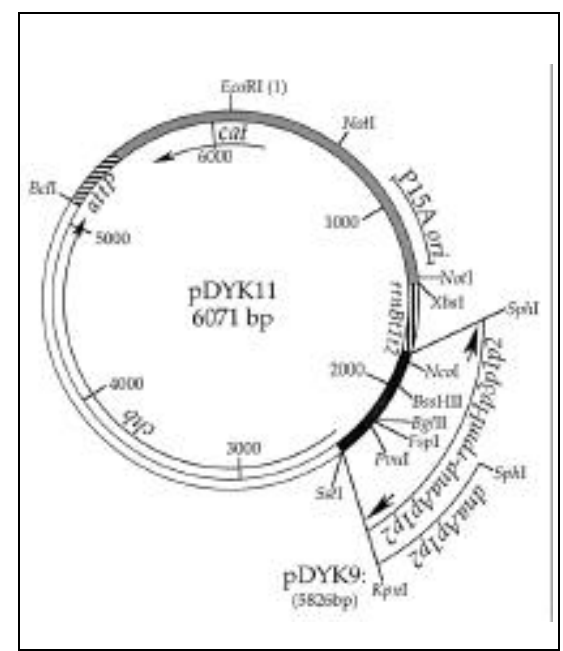

Figure 4. Plasmids pDYK9 and pDYK11 containing $\boldsymbol{d n} \boldsymbol{a} \boldsymbol{A}$ - $\boldsymbol{c h b}$ fusions. pDYK9 is deleted for the $r p m H$ regulatory region. The orientation of att $P$ in $\mathrm{pDYK} 9$ and $\mathrm{pDYK} 11$ is the same as that of pJMF3 (see Figure 1). After integration at $a t t B$ of the larger NotI fragment, the dnaA promoters are oriented to transcribe in the same direction as the replication fork. 


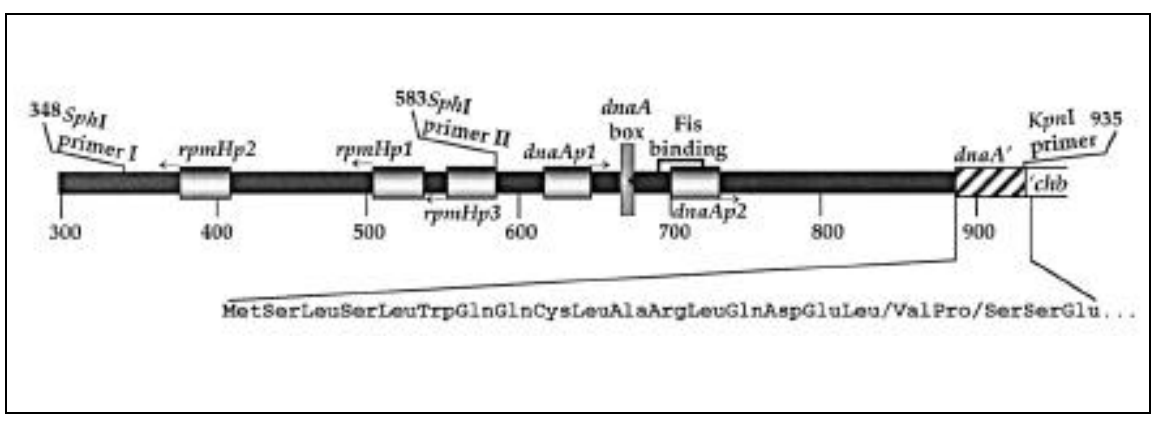

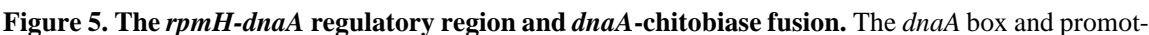
ers are shaded, and the coding region of the $d n a A$ gene is striped. The fusion contains two aa (between the backslashes) from pUC19. The region cloned into pDYK9 is between $S p h$ I primer II and KpnI primer, and the region cloned into pDYK11 is between $S p h \mathrm{I}$ primer I and $K p n \mathrm{I}$ primer. The numbers above the primers refer to the nucleotide in the sequence amplified. See References 8,10 and 12 for sequence numbering and locations of promoters and protein-binding sites.

strain construction is greatly facilitated when no other mutations are required. In the case of the lac $Z$ reporter gene, more steps would be necessary to construct the appropriate isogenic strains.

The P15A origin of replication on these vectors is compatible with all ColE1- and pMB1-derived origins. This permits one to introduce a putative regulatory protein by a compatible plasmid and to assay its effect on the promoter driving the $c h b$ fusion.

Chitobiase activity can be readily measured with commercially available substrates. Chitobiase-producing colonies are blue on plates that contain $\mathrm{X}$ Gluc, and colonies that do not produce chitobiase are white. Quantitative measurements of chitobiase activity can be performed with either PNAG or chitobiose as the substrate $(11,16)$, thereby measuring the level of promoter activity.

In our constructs, all upstream transcriptional activity is prevented from entering the $c h b$ reporter gene. The plasmid vectors, pJMF3 and pJMF4, contain the rrnbtlt 2 terminator upstream of the promoter fusion, which prevents read-through from chromosomal promoters near the insertion site. Only chitobiase activity originating from the promoters of interest is expressed.

The attP site in these vectors allows integration at the chromosomal $a t t B$ in a specific orientation, depending on the vector used. With these vectors, any chitobiase fusion involving an essential gene can be moved to the chromosome, thus permitting single-copy analysis with a chromosomal orientation similar to the WT gene.

\section{ACKNOWLEDGMENTS}

We wish to thank Reid Johnson, Andrew Wright, Walter Messer and Doug Smith for strains and plasmids. We are especially appreciative of the many suggestions and materials provided by Anca Segall. These studies were supported by National Science Foundation Grant No. MCB-9507209 (J.W.Z.). T.K.P. was a trainee supported by the National Institutes of Health (NIH) MBRS Grant No. GM45765, and R.A.F. was a Predoctoral Fellow supported by the NIH National Institute of General Medical Sciences MARC F31 GM14967-0451.

\section{REFERENCES}

1.Ball, C.A., R. Osuna, K.C. Ferguson and R.C. Johnson. 1992. Dramatic changes in Fis levels upon nutrient upshift in Escherichia coli. J. Bacteriol. 174:8043-8056.

2.Braun, R.E., K. O'Day and A. Wright. 1985. Autoregulation of the DNA replication gene dnaA in E. coli K-12. Cell 40:159-169.

3.Brosius, J., T.J. Dull, D.D. Sleeter and H.F. Noller. 1981. Gene organization and primary structure of a ribosomal RNA operon from $E s$ cherichia coli. J. Mol. Biol. 148:107-127

4.Chang, A.C.Y. and S. Cohen. 1987. Construction and characterization of amplifiable multicopy DNA cloning vehicles derived from the p15A cryptic miniplasmid. J. Bacteriol. 134:1141-1156.

5.Chiaramello, A.E. and J.W. Zyskind. 1992. Coupling of DNA replication to growth rate in Escherichia coli: a possible role for guanosine tetraphosphate. J. Bacteriol. 172:2013-2019.

6.Dickson, R.C., J. Abelson, W.M. Barnes and W.S. Reznikoff. 1975. Genetic regulation: the Lac control region. Science 187:27-32.

7.Diederich, L.L., J. Rasmussen and W. Messer. 1992. New cloning vectors for integration into the $\lambda$ attachment site $a t t B$ of Escherichia coli chromosome. Plasmid 28:14-24.

8.Froelich, J.M., T.P. Phuong and J.W. Zyskind. 1996. Fis binding in the dnaA operon promoter region. J. Bacteriol. 178:60066012.

9.Goodman, S.D., S.C. Nicholson and H.A. Nash. 1992. Deformation of DNA during sitespecific recombination of bacteriophage lambda: replacement of IHF protein by $\mathrm{HU}$ protein or sequence-directed bends. Proc. Natl. Acad. Sci. USA 89:11910-11914.

10.Hansen, F.G., E.B. Hansen and T. Atlung. 1982. The nucleotide sequence of the dnaA gene promoter and of the adjacent rpmH gene, coding for the ribosomal protein L34, of Escherichia coli. EMBO J. 1:1043-1048.

11.Jannatipour, M., R.W. Soto-Gil, L.C. Childers and J.W. Zyskind. 1995. Translocation of Vibrio harveyi $N, N^{\prime}$-diacetylchitobiase to the outer membrane of Escherichia coli. J. Bacteriol. 169:3785-3791.

12.Messer, W. and C.W. Weigel. 1996. Initiation of chromosome replication, p. 1579-1601. In F.C. Neidhardt, R. Curtiss III, J.L. Ingraham, E.C.C. Lin, K.B. Low, B. Magasanik, W.S. Reznikoff, M. Riley, M. Schaechter and H.E. Umbarger (Eds.), Escherichia coli and Salmonella Cellular and Molecular Biology. ASM Press, Washington, DC.

13.Miller, J.H. 1992. A Short Course in Bacterial Genetics. CSH Laboratory Press, Cold Spring Harbor, NY.

14.Nagaraja, R. and R.A. Weisberg. 1990. Specificity determinants in the attachment sites of bacteriophages HK022 and $\lambda$. J. Bacteriol. 172:6540-6550.

15.Orosz, A., I. Boros and P. Venetianer. 1991. Analysis of the complex transcription termination region of the Escherichia coli $\mathrm{rrnB}$ gene. Eur. J. Biochem. 201:653-659

16.Soto-Gil, R.W., L.C. Childers, W.H. Huisman, A.S. Dahms, M. Jannatipour, F. Hedjran and J.W. Zyskind. 1988. $N, N^{\prime}$-Diacetylchitobiase of Vibrio harveyi. Methods Enzymol. 161:524-529.

17.Soto-Gil, R.W. and J.W. Zyskind. 1989. $N, N^{\prime}$-Diacetylchitobiase of Vibrio harveyi primary structure, processing, and evolutionary relationships. J. Biol Chem. 264:1477814782.

18.Yanisch-Perron, C., J. Vieira and J. Messing. 1985. Improved M13 phage cloning vectors and host strains: nucleotide sequences of the M13mp18 and pUC19 vectors. Gene 33:103-119.

19.Zyskind, J.W. and S.I. Bernstein. 1992. Recombinant DNA Laboratory Manual. Academic Press, San Diego.

Received 11 May 1998; accepted 7 July 1998.

\section{Address correspondence to:}

Judith W. Zyskind

Biology Department

San Diego State University

San Diego, CA 92182-4614, USA

Internet: jzyskind@sunstroke.sdsu.edu 